\title{
The Impact of COVID-19 on the Optimal Management of Osteoporosis
}

\author{
Sung Hye Kong ${ }^{1}$, Bo Kwon Hwang ${ }^{2}$, Byung-Ho Yoon ${ }^{2}$ \\ 'Department of Internal Medicine, Seoul National University Bundang Hospital, Seoul National University College of Medicine, Seoul; \\ ${ }^{2}$ Department of Orthopedic Surgery, Ewha Womans University, College of Medicine, Mokdong Hospital, Seoul, Korea
}

\author{
Corresponding author \\ Byung-Ho Yoon \\ Department of Orthopedic Surgery, Ewha \\ Womans University Mokdong Hospital, \\ 1071 Anyangcheon-ro, Yangcheon-gu, Seoul \\ 07985, Korea \\ Tel: +82-2-2650-5276 \\ Fax: +82-2-2642-0349 \\ E-mail: cragy0215@naver.com
}

Received: April 29, 2021

Revised: May 17, 2021

Accepted: May 20, 2021
Osteoporosis does not take a break while Coronavirus disease 2019 (COVID-19) stunned and overtook everyone's lives. Medical resources were immediately shifted, self-isolation and telemedicine were expanded, ambulatory care services such as bone densitometry and osteoporosis-centered clinics came to a near halt. Progress with fracture prevention has been challenged because osteoporotic fracture with low energy injury is more prevalent even though restriction of people's movement. Thus we must re-engage with chronic bone health concerns and fracture prevention. This review discusses challenges in management of osteoporosis during the COVID-19 pandemic and reinforces the need to implementing recommendations concerning the importance of bone fragility care with at least those patients who are already treated with antiosteoporotic drugs maintaining their adherence to treatments.

Key Words: COVID-19 · Epidemics · Osteoporosis · Osteoporotic fractures

\section{INTRODUCTION}

Osteoporotic fracture (OF) represents a public health issue affecting $30 \%$ of women and $20 \%$ of men aged $>50$ years, and staying fracture-free is critical for anyone with osteoporosis, now more than ever.[1] Its consequences include short and long-term morbidities such as pain, limitation of function, decreased healthrelated quality of life, and increased mortality, so prevention of OF ultimately lead to reduction in morbidity and mortality.[2-4] However, the global Coronavirus disease 2019 (COVID-19) pandemic has greatly affected the prevention and care of osteoporosis, one of the most common chronic diseases.[5-7] Healthcare systems are over-stretched, with general recommendations urging people to avoid hospitals and doctor's offices unless necessary.[3,8]

Despite a massive drop in medical care use, OFs continue to be a major burden on morbidity as well as the social-economic burden and decrease the quality of life.[9] Compared to admissions in persons older than 60 (excluding those related to COVID-19) declined $40 \%$, admissions for fragility fractures declined only $15 \%$, and hip fractures (HFs; age > 60) declined just $10 \%$ in the same time period of the previous year.[10,11] As part of that, International Osteoporosis Foundation (IOF) has recently developed various educational resources and information to assist healthcare professionals, patient societies, and patients in adapting to the chal-

\section{Mineral Research}

This is an Open Access article distributed under the terms of the Creative Commons Attribution Non-Commercial License (https://creativecommons.org/licenses/by-nc/4.0/) which permits unrestricted non-commercial use, distribution, and reproduction in any medium, provided the origina work is properly cited.

\section{KSBMR}


lenges related to assessment, treatment and lifestyle prevention for osteoporosis.[12] COVID-19 is still a main worldwide public health threat and a "second wave" which could occur through the winter months of 2021.[13]

Herein, we discuss challenges and strategies in the management of osteoporosis and fragility fracture care during COVID-19 pandemic.

\section{TREND OF OSTEOPOROTIC FRACTURE IN COVID-19 PANDEMIC}

Many countries implemented a lockdown to control the spread of the COVID-19 pandemic. The epidemiological characteristics of traumatic fractures amid the epidemic changes dramatically, but it is unknown whether the restriction of outdoor movements (lockdown) may affect the incidence of osteoporotic fragility fractures by potentially reducing the number of outdoor falls and subsequent fractures among older adults.

Vertebral fractures (VFs) are clinically meaningful because impaired pulmonary function is associated with spine deformities, so a potential outcome predictor of COVID-19 infection may be the presence of VF.[14,15] One study reported that the prevalence of VF was much higher as compared with epidemiological data reported in previous studies on general populations.[16] Thus, it is suggested that morphometric vertebral evaluation should be performed in all suspected COVID-19 patients undergoing chest Xrays.[16] The average number of attending for osteoporotic VF did not decline during a lockdown, although older people may decide not to attend the fracture clinic for fear contracting COVID-19 in a hospital environment.[9]

With elderly people cocooning, going outside less, and minimising a lot of their activities both inside and outside, one would expect there to be less HFs presentations during the "lockdown" isolation period for COVID-19. There is a study that comparing number of HF with a similar time period in 2019, and there was a $20 \%$ reduction in HF presentations.[10] This does appear to be consistent with other jurisdictions, which have noted a $32 \%$ reduction in trauma presentations during the COVID-19 pandemic.[17] However, $\mathrm{HF}$ is still a major burden, one study showed that HFs were the most common type of OF in the epidemic patient group, accounting for $68.4 \%$, followed by thoracolumbar VF (17.0\%) and similar observations have been made in- ternationally.[10,17] Moreover the combination of osteoporotic HF and COVID-19 is associated with very poor outcomes. A positive COVID-19 test was associated with a significantly increased risk of 30-day mortality (from $8.5 \%$ in April 2019 to $18.2 \%$ in April 2020) and even upto $80 \%$ for those patients who test positive for COVID-19 as an inpatient. $[17,18]$ In that sense, it is notable that redeployment of secondary prevention of osteoporotic HF significantly improve management of bone health compared to the post lockdown period and was comparable to the prelockdown data.[19]

\section{THE RISK OF OSTEOPOROTIC FRACTURE IN COVID-19 PANDEMIC}

Although recent advances in osteoporosis management have brought better opportunities to increase bone density and reduce the risk of fractures, it is likely to increase the risk of OF after the COVID-19 pandemic by straining the healthcare system in an emergency and discontinuation appropriate treatment for patients with chronic diseases. $[2,11]$

Access to osteoporosis treatments often require direct medical contact, so it can be delayed or missed, especially in the case of intravenous or subcutaneous antiresorptives. [20] This leads to increased risk of further fracture particularly and case series suggest that the risk of rebound increase in bone turnover and spontaneous VFs begins approximately 8 months following the last dose of denosumab.[21] The detrimental effect of the pandemic on osteoporosis is not only confined to a reduction in medical usage but risk assessment. The usages of the fracture risk assessment tool (FRAX) website for the periods of 2020 decreased, averaging $58 \%$ and ranging up to $96 \%$, compared to the year of 2019.[22] Also, several fracture liaison services have been disrupted, compromising secondary fracture prevention. $[23,24]$

Many facilities are dedicated to the COVID-19 crisis, and elective radiology including dual energy $\mathrm{X}$-ray absorptiometry may be severely limited. In addition hospitalized COVID-19 patients deserve special care because they have multiple predisposing factors to OF such as high levels of inflammatory cytokines, several comorbidities, and glucocorticoid therapy. $[5,25]$ It is advisable to determine the absolute risk of fracture of each patient, particularly including 
selected laboratory tests and assess the factors associated with fracture susceptible to modification. $[8,26]$ The exact impact of the extended pandemic on the risk of future OF is still is unknown, but it is essential to maintain the importance of osteoporosis care despite emergency management during the COVID-19 pandemic.[5,22]

\section{STRATEGIES IN NONPHARMACOLOGICAL TREATMENT}

Management of patients with osteoporosis usually includes both nonpharmacologic and pharmacologic treatment. Among various nonpharmacologic treatments for osteoporosis, weight-bearing exercise is essential for improving strength and balance, which may reduce the risk of falls and fractures.[27-29] However, patients can hardly access local gyms or exercise programs because of the social distancing during the pandemic. Therefore, patients should be advised on simple weight-bearing exercise routines that can be performed at home.[4,30] Patients can be directed to online resources, such as the IOF (https://www. iofbonehealth.org/exercise), the National Osteoporosis Foundation (https://www.nof.org/patients/treatment/exercisesafe-movement/osteoporosis-exercise-for-strongbones/), and the American Society of Bone and Mineral Research COVID-19 Resources (https://www.asbmr.org/ publications/asbmr-covid-19-resources-and-information). For Korean patients, there are online resources of light and simple weight-bearing exercise tutorials in the Korean language produced by the Korean Society of Bone and Mineral Research (https://vimeo.com/244299068/86a2fd65b3). In practice, treatment adherence should be routinely emphasized to the patients, especially in the pandemic that patients are reluctant or inaccessible to clinics. Emphasizing treatment adherence is becoming critical not only for successful treatment but also for the safety of specific treatments, as discussed in the next section.

\section{STRATEGIES IN PHARMACOLOGICAL TREATMENT}

\section{Bisphosphonates}

Especially in individuals at high risk of COVID-19 infection, the risk of an acute-phase reaction should be carefully discussed with patients before using bisphosphonates, which can mimic the signs of COVID-19 infection.[4,31,32] In treatment-naïve patients, the risk of acute-phase reaction with fever and myalgia is substantial, affecting up to $50 \%$ of these patients.[33-35] Several attempts to reduce the risk of the acute-phase reaction have been tried but demonstrated variable success.[36-38]

On the other hand, if patients are already under the treatment of bisphosphonates and cannot visit clinics on schedule, they may safely delay the treatment for several months. Unlike denosumab, bone turnover markers gradually return to the baseline after bisphosphonate discontinuation, and bone mineral density (BMD) maintains or slowly decreases over the years.[39,40] Also, the protective effect on fracture persisted and showed no difference compared to persistent users.[41] The phenomenon is due to the high binding affinity of bisphosphonates to hydroxyapatite, which maintains the antiresorptive effect.[42]

\section{Denosumab}

Patients under denosumab treatment should continue their treatment in a 6-monthly interval, and self-injections can be considered in unavoidable circumstances, likewise in the pandemic.[30,31] In patients who are unable to continue denosumab within 7 months of the last injection, a temporary transition to oral bisphosphonates is strongly recommended.[4,30,31] There is growing evidence that denosumab cessation without following bisphosphonates can cause a rapid bone loss with a rebound surge of bone resorption.[43,44] Additionally, it leads to an increased risk of multiple compression fractures, which mainly occurred after 7 months of the last injection of denosumab.[45,46] The ideal regimen of bisphosphonates to prevent rebound bone loss after denosumab discontinuation is currently being studied in several trials.[47-49] Alendronate as the following treatment has relatively consistent evidence to protect from rebound bone loss, $[47,48]$ while zoledronate has been shown to be less effective in maintaining BMD, notably when the duration of denosumab treatment exceeds 2 years.[50,51] Other antiresorptives, such as selective estrogen receptor modulators, may prevent bone loss after denosumab discontinuation, needing further largesized studies.[52]

\section{Parathyroid hormone analogues}

Patients currently on teriparatide are recommended to 
Table 1. Summary of pharmacologic strategies of osteoporosis during COVID-19

\begin{tabular}{ll}
\hline Drugs & \multicolumn{1}{c}{ Strategies } \\
\hline Bisphosphonates & - Patients under the treatment of intravenous bisphosphonates who cannot visit clinics on schedule may safely delay the treat- \\
& ment for several months. \\
& - Intravenous bisphosphonates are empirically recommended to have 4 to 7 days interval between bisphosphonates and vaccine \\
& due to the possibility of acute phase reaction. \\
- Oral bisphosphonates do not need to be discontinued during vaccination. & - Patients under denosumab treatment should continue their treatment in a 6 -monthly interval. Self-injections or a temporary \\
& transition to oral bisphosphonates can be considered if they cannot visit within 7 months of the last injection. \\
Denosumab & - Since denosumab can cause injection site reactions, injections are recommended be administered at contralateral arms or \\
& different sites, or with 4 to 7 days of interval. \\
Parathyroid hormone & - Patients currently on teriparatide are recommended to continue their planned therapy, but the treatment schedule can be \\
analogues & delayed for up to 3 months. \\
& - If the delay is likely to be longer than 3 months, transition to bisphosphonates can be considered. \\
- & Teriparatide and abaloparatide can be continued during vaccination. \\
Romosozumab & For patients under treatment with romosozumab, treatment should not be delayed for more than 2 to 3 months as far as pos- \\
& sible. In such circumstances, a transition to bisphosphonates or self-injection of denosumab can be considered. \\
& - Romosozumab injections are recommended be administered with 4 to 7 days of interval to vaccination, or at alternative sites \\
& such as abdomen or thigh.
\end{tabular}

continue their planned therapy, but the treatment schedule can be delayed for up to 3 months in unavoidable circumstances.[4,31] If the delay is likely to be longer than 3 months, transition to bisphosphonates can be considered. Although there is a lack of evidence of increased fracture risk, BMD slowly decreases following teriparatide cessation.[53] Therefore, to maintain the beneficial anti-fracture effects, it is recommended to continue antiresorptive agents following the treatment discontinuation, which leads to further BMD gain in previous studies.[54-57] On the other hand, cyclic teriparatide treatment ( 3 months of treatment followed by 3 months off) showed a similar increase in BMD compared to daily treatment, which implies discontinuation of teriparatide within 3 months is unlikely to cause harm to patients.[58]

\section{Romosozumab}

For patients under treatment with romosozumab, treatment should not be delayed for more than 2 to 3 months as far as possible. In such circumstances, a transition to bisphosphonates or denosumab can be considered.[31] Also, for patients who are uncertain to visit clinics monthly, initiation of romosozumab should be reconsidered, and bisphosphonates is an alternative option. Not as abrupt as denosumab, but similarly, a rapid bone loss was observed after romosozumab discontinuation, if not followed by antiresorptive agents.[59-61] While there was no evidence of increased fracture risk, bone resorption markers were elevated within 3 months of discontinuation.[59] Switching treatment from romosozumab to alendronate or denosumab has been reported to increase BMD continuously. $[60,61]$ The Pharmacologic strategies of osteoporosis during COVID-19 were summarized in Table 1.

\section{STRATEGIES IN VACCINATION}

Recently, multiple vaccines for COVID-19 have been introduced and are rapidly distributed worldwide. Concerns have been raised about the potential interactions of vaccines with osteoporotic drugs. For intravenous bisphosphonates, while there is no evidence to suggest the concurrent administration of vaccine and bisphosphonates alters each other's efficacy, it is empirically recommended to have 4 to 7 days interval between bisphosphonates and vaccine due to the possibility of acute-phase reaction.[62] Also, if patients who received intravenous bisphosphonates have fever or myalgia over 3 days, evaluation for COVID-19 infection should be considered since the acute phase reaction of bisphosphonates rarely extends over 3 days. [63] Oral bisphosphonates do not need to be discontinued during vaccination. In terms of denosumab, there is no evidence that denosumab was associated with risk of respiratory infections in a recent meta-analysis.[64] However, since denosumab can cause injection site dermatitis or eczema,[65] injections 
are recommended to be administered at contralateral arms or different sites, or with 4 to 7 days of interval.[62] Teriparatide and abaloparatide may also induce local injection site reactions but usually do not cause confusion because the injection sites are different from those of vaccines.[66] Therefore, teriparatide and abaloparatide can be continued during vaccination. Since Romosozumab also can cause injection site reactions at the upper arms,[67] the reactions can be indistinguishable to those of vaccines. Therefore, similar to denosumab, injections are recommended to be administered with 4 to 7 days of interval or at alternative sites such as abdomen or thigh.[62]

\section{CONCLUSION}

In the review, challenges and strategies in management of osteoporosis and fragility fracture care during COVID-19 pandemic were discussed. In these unprecedented circumstances, medical usage of risk assessment, treatment, and fracture liaison services was significantly disrupted, which can impact an increased risk of fractures especially in fragile elderly patients. For their bone health, strategies include maintaining physical activity and strict adherence to the certain osteoporosis medication, especially denosumab and romosozumab. Parathyroid hormone analogues and bisphosphonates can be safely delayed within few months. The vaccination should be prioritized over osteoporosis treatments, and intervals of 4 to 7 days can be considered between the vaccination and certain osteoporosis drugs, such as intravenous bisphosphonates, denosumab, and romosozumab. Hopefully the review may help clinicians as practical guidance in the care of bone health of our patients in the setting of this widespread pandemic.

\section{DECLARATIONS}

\section{Funding}

The authors received no financial support for this article.

\section{Ethics approval and consent to participate Not applicable.}

\section{Conflict of interest}

No potential conflict of interest relevant to this article was reported.
ORCID

Sung Hye Kong https://orcid.org/0000-0002-8791-0909

Byung-Ho Yoon https://orcid.org/0000-0001-8518-6331

\section{REFERENCES}

1. Yoon BH, Lee JK, Choi DS, et al. Prevalence and associated risk factors of sarcopenia in female patients with osteoporotic fracture. J Bone Metab 2018;25:59-62. https://doi. org/10.11005/jbm.2018.25.1.59.

2. Teng GG, Curtis JR, Saag KG. Mortality and osteoporotic fractures: is the link causal, and is it modifiable? Clin Exp Rheumatol 2008;26:S125-37.

3. Tarantino U, Cariati I, Tancredi V, et al. State of fragility fractures management during the COVID-19 pandemic. Int J Environ Res Public Health 2020;17. https://doi.org/10.3390/ ijerph17217732.

4. Girgis CM, Clifton-Bligh RJ. Osteoporosis in the age of COVID-19. Osteoporos Int 2020;31:1189-91. https://doi.org/ 10.1007/s00198-020-05413-0.

5. Narla RR, Adler RA. Osteoporosis care amidst the prolonged pandemic. J Endocrinol Invest 2021. https://doi.org/10.1007/ s40618-021-01542-3.

6. Pal R, Bhadada SK. Managing common endocrine disorders amid COVID-19 pandemic. Diabetes Metab Syndr 2020; 14:767-71. https://doi.org/10.1016/j.dsx.2020.05.050.

7. Ren $Y$, Song $X$, Tan L, et al. A review of the pharmacological properties of psoralen. Front Pharmacol 2020;11:571535. https://doi.org/10.3389/fphar.2020.571535.

8. Wosik J, Fudim M, Cameron B, et al. Telehealth transformation: COVID-19 and the rise of virtual care. J Am Med Inform Assoc 2020;27:957-62. https://doi.org/10.1093/ jamia/ocaa067.

9. Ogliari G, Lunt E, Ong T, et al. The impact of lockdown during the COVID-19 pandemic on osteoporotic fragility fractures: an observational study. Arch Osteoporos 2020;15:156. https://doi.org/10.1007/s11657-020-00825-1.

10. Jarvis S, Salottolo K, Madayag R, et al. Delayed hospital admission for traumatic hip fractures during the COVID-19 pandemic. J Orthop Surg Res 2021;16:237. https://doi.org/ 10.1186/s13018-021-02382-w.

11. Falchetti A, Mohseni M, Tramontana F, et al. Secondary prevention of fragility fractures: where do we stand during the COVID-19 pandemic? J Endocrinol Invest 2021. https://doi.org/10.1007/s40618-021-01552-1. 
12. International Osteoporosis Foundation. Osteoporosis \& COVID-19. 2021 [cited by 2021 Mar 1]. Available from: https://www.osteoporosis.foundation/osteoporosis-andcovid19

13. Moghnieh R, Abdallah D, Bizri AR. COVID-19: Second wave or multiple peaks, natural herd immunity or vaccine - We should be prepared. Disaster Med Public Health Prep 2020. https://doi.org/10.1017/dmp.2020.349.

14. Bhattacharyya T. Osteoporotic fractures in the time of COVID-19. J Bone Miner Res 2020;35:2083. https://doi.org/ 10.1002/jbmr.4113.

15. Goldstein CL, Chutkan NB, Choma TJ, et al. Management of the elderly with vertebral compression fractures. Neurosurgery 2015;77 Suppl 4:S33-45. https://doi.org/10.1227/ neu.0000000000000947.

16. di Filippo L, Formenti AM, Doga M, et al. Radiological thoracic vertebral fractures are highly prevalent in COVID-19 and predict disease outcomes. J Clin Endocrinol Metab 2021;106:e602-e14. https://doi.org/10.1210/clinem/dgaa 738.

17. Crozier-Shaw G, Hughes AJ, Conlon B, et al. Hip fracture care during Covid-19: a regional trauma centre's experience. Ir J Med Sci 2021. https://doi.org/10.1007/s11845020-02476-0.

18. Barker T, Thompson J, Corbett J, et al. Increased 30-day mortality rate in patients admitted with hip fractures during the COVID-19 pandemic in the UK. Eur J Trauma Emerg Surg 2021. https://doi.org/10.1007/s00068-021-01649-5.

19. Stephens A, Rudd H, Stephens E, et al. Secondary prevention of hip fragility fractures during the COVID-19 pandemic: Service evaluation of "MRS BAD BONES". JMIR Aging 2020;3:e25607. https://doi.org/10.2196/25607.

20. Kocijan R, Behanova $M$, Reichardt $B$, et al. Poor adherence to parenteral osteoporosis therapies during COVID-19 pandemic. Arch Osteoporos 2021;16:46. https://doi.org/10.1007/ s11657-021-00904-X.

21. Anastasilakis AD, Polyzos SA, Makras $P$, et al. Clinical features of 24 patients with rebound-associated vertebral fractures after denosumab discontinuation: Systematic review and additional cases. J Bone Miner Res 2017;32: 1291-6. https://doi.org/10.1002/jbmr.3110.

22. McCloskey EV, Harvey NC, Johansson H, et al. Global impact of COVID-19 on non-communicable disease management: descriptive analysis of access to FRAX fracture risk online tool for prevention of osteoporotic fractures.
Osteoporos Int 2021;32:39-46. https://doi.org/10.1007/ s00198-020-05542-6.

23. Geiger I, Kammerlander C, Höfer C, et al. Implementation of an integrated care programme to avoid fragility fractures of the hip in older adults in 18 Bavarian hospitals study protocol for the cluster-randomised controlled fracture liaison service FLS-CARE. BMC Geriatr 2021;21:43. https://doi.org/10.1186/s12877-020-01966-1.

24. English S, Coyle L, Bradley S, et al. Virtual fracture liaison clinics in the COVID era: an initiative to maintain fracture prevention services during the pandemic associated with positive patient experience. Osteoporos Int 2021;32:12216. https://doi.org/10.1007/s00198-021-05882-x.

25. Fuggle NR, Singer A, Gill C, et al. How has COVID-19 affected the treatment of osteoporosis? An IOF-NOF-ESCEO global survey. Osteoporos Int 2021;32:611-7. https://doi.org/ 10.1007/s00198-020-05793-3.

26. Zhang B, Zhang S. Corticosteroid-induced osteonecrosis in COVID-19: A call for caution. J Bone Miner Res 2020;35: 1828-9. https://doi.org/10.1002/jbmr.4136.

27. Howe TE, Shea B, Dawson LJ, et al. Exercise for preventing and treating osteoporosis in postmenopausal women. Cochrane Database Syst Rev 2011;7:CD000333. https:// doi.org/10.1002/14651858.CD000333.pub2.

28. Nanduri AP, Fullman S, Morell L, et al. Pilot study for implementing an osteoporosis education and exercise program in an assisted living facility and senior community. J Appl Gerontol 2018;37:745-62. https://doi.org/10.1177/07334 64816672045.

29. Watson SL, Weeks BK, Weis LJ, et al. High-intensity resistance and impact training improves bone mineral density and physical function in postmenopausal women with osteopenia and osteoporosis: The LIFTMOR randomized controlled trial. J Bone Miner Res 2018;33:211-20. https:// doi.org/10.1002/jbmr.3284.

30. Gittoes NJ, Criseno S, Appelman-Dijkstra NM, et al. Endocrinology in the time of COVID-19: Management of calcium metabolic disorders and osteoporosis. Eur J Endocrinol 2020;183:G57-G65. https://doi.org/10.1530/eje-200385.

31. Yu EW, Tsourdi E, Clarke BL, et al. Osteoporosis management in the era of COVID-19. J Bone Miner Res 2020;35: 1009-13. https://doi.org/10.1002/jbmr.4049.

32. Byun JH, Jang S, Lee $S$, et al. The efficacy of bisphosphonates for prevention of osteoporotic fracture: An update 
meta-analysis. J Bone Metab 2017;24:37-49. https://doi. org/10.11005/jbm.2017.24.1.37.

33. Popp AW, Senn R, Curkovic I, et al. Factors associated with acute-phase response of bisphosphonate-naïve or pretreated women with osteoporosis receiving an intravenous first dose of zoledronate or ibandronate. Osteoporos Int 2017;28:1995-2002. https://doi.org/10.1007/s00198017-3992-5.

34. Anastasilakis AD, Polyzos SA, Makras $P$, et al. Acute phase response following intravenous zoledronate in postmenopausal women with low bone mass. Bone 2012;50:11304. https://doi.org/10.1016/j.bone.2012.02.006.

35. Crotti C, Watts NB, De Santis M, et al. Acute phase reactions after zoledronic acid infusion: Protective role of 25-hydroxyvitamin $d$ and previous oral bisphosphonate therapy. Endocr Pract 2018;24:405-10. https://doi.org/10.4158/ep161 638.Or.

36. Chen FP, Fu TS, Lin YC, et al. Addition of dexamethasone to manage acute phase responses following initial zoledronic acid infusion. Osteoporos Int 2021;32:663-70. https:// doi.org/10.1007/s00198-020-05653-0.

37. Billington EO, Horne A, Gamble GD, et al. Effect of singledose dexamethasone on acute phase response following zoledronic acid: a randomized controlled trial. Osteoporos Int 2017;28:1867-74. https://doi.org/10.1007/s00198-0173960-0.

38. Makras $P$, Anastasilakis AD, Polyzos SA, et al. No effect of rosuvastatin in the zoledronate-induced acute-phase response. Calcif Tissue Int 2011;88:402-8. https://doi.org/ 10.1007/s00223-011-9468-2.

39. Black DM, Reid IR, Boonen S, et al. The effect of 3 versus 6 years of zoledronic acid treatment of osteoporosis: a randomized extension to the HORIZON-Pivotal Fracture Trial (PFT). J Bone Miner Res 2012;27:243-54. https://doi.org/ 10.1002/jbmr.1494.

40. Black DM, Delmas PD, Eastell R, et al. Once-yearly zoledronic acid for treatment of postmenopausal osteoporosis. N Engl J Med 2007;356:1809-22. https://doi.org/10.1056/ NEJMoa067312.

41. Nayak S, Greenspan SL. A systematic review and metaanalysis of the effect of bisphosphonate drug holidays on bone mineral density and osteoporotic fracture risk. Osteoporos Int 2019;30:705-20. https://doi.org/10.1007/ s00198-018-4791-3.

42. Henneman ZJ, Nancollas GH, Ebetino FH, et al. Bisphos- phonate binding affinity as assessed by inhibition of carbonated apatite dissolution in vitro. J Biomed Mater Res A 2008;85:993-1000. https://doi.org/10.1002/jbm.a.31599.

43. Miller PD, Wagman RB, Peacock M, et al. Effect of denosumab on bone mineral density and biochemical markers of bone turnover: six-year results of a phase 2 clinical trial. J Clin Endocrinol Metab 2011;96:394-402. https://doi.org/ 10.1210/jc.2010-1805.

44. Bone HG, Bolognese MA, Yuen CK, et al. Effects of denosumab treatment and discontinuation on bone mineral density and bone turnover markers in postmenopausal women with low bone mass. J Clin Endocrinol Metab 2011; 96:972-80. https://doi.org/10.1210/jc.2010-1502.

45. Cummings SR, Ferrari S, Eastell R, et al. Vertebral fractures after discontinuation of denosumab: A post hoc analysis of the randomized placebo-controlled FREEDOM trial and its extension. J Bone Miner Res 2018;33:190-8. https://doi. org/10.1002/jbmr.3337.

46. Tsourdi E, Zillikens MC, Meier C, et al. Fracture risk and management of discontinuation of denosumab therapy: a systematic review and position statement by ECTS. J Clin Endocrinol Metab 2020. https://doi.org/10.1210/clinem/dgaa756.

47. Freemantle N, Satram-Hoang S, Tang ET, et al. Final results of the DAPS (Denosumab Adherence Preference Satisfaction) study: a 24-month, randomized, crossover comparison with alendronate in postmenopausal women. Osteoporos Int 2012;23:317-26. https://doi.org/10.1007/s00198011-1780-1.

48. Kendler D, Chines A, Clark P, et al. Bone mineral density after transitioning from denosumab to alendronate. J Clin Endocrinol Metab 2020;105:e255-64. https://doi.org/10.1210/ clinem/dgz095.

49. Anastasilakis AD, Papapoulos SE, Polyzos SA, et al. Zoledronate for the prevention of bone loss in women discontinuing denosumab treatment. A prospective 2-year clinical trial. J Bone Miner Res 2019;34:2220-8. https://doi.org/ 10.1002/jbmr.3853.

50. Reid IR, Horne AM, Mihov B, et al. Bone loss after denosumab: Only partial protection with zoledronate. Calcif Tissue Int 2017;101:371-4. https://doi.org/10.1007/s00223017-0288-x.

51. Everts-Graber J, Reichenbach S, Ziswiler HR, et al. A single infusion of zoledronate in postmenopausal women following denosumab discontinuation results in partial con- 
servation of bone mass gains. J Bone Miner Res 2020;35: 1207-15. https://doi.org/10.1002/jbmr.3962.

52. Ebina K, Hashimoto J, Kashii M, et al. Effects of follow-on therapy after denosumab discontinuation in patients with postmenopausal osteoporosis. Mod Rheumatol 2021;31: 485-92. https://doi.org/10.1080/14397595.2020.1769895.

53. Leder BZ, Neer RM, Wyland JJ, et al. Effects of teriparatide treatment and discontinuation in postmenopausal women and eugonadal men with osteoporosis. J Clin Endocrinol Metab 2009;94:2915-21. https://doi.org/10.1210/jc.20082630.

54. Leder BZ, Tsai JN, Uihlein AV, et al. Denosumab and teriparatide transitions in postmenopausal osteoporosis (the DATA-Switch study): extension of a randomised controlled trial. Lancet 2015;386:1147-55. https://doi.org/10.1016/ s0140-6736(15)61120-5.

55. Rittmaster RS, Bolognese M, Ettinger MP, et al. Enhancement of bone mass in osteoporotic women with parathyroid hormone followed by alendronate. J Clin Endocrinol Metab 2000;85:2129-34. https://doi.org/10.1210/jcem.85. 6.6614.

56. Kurland ES, Heller SL, Diamond B, et al. The importance of bisphosphonate therapy in maintaining bone mass in men after therapy with teriparatide [human parathyroid hormone(1-34)]. Osteoporos Int 2004;15:992-7. https://doi. org/10.1007/s00198-004-1636-z.

57. Burkard D, Beckett T, Kourtjian E, et al. Effects of bone remodeling agents following teriparatide treatment. Osteoporos Int 2018;29:1351-7. https://doi.org/10.1007/s00198018-4434-8.

58. Cosman F, Nieves JW, Zion M, et al. Daily or cyclical teriparatide treatment in women with osteoporosis on no prior therapy and women on alendronate. J Clin Endocrinol Metab 2015;100:2769-76. https://doi.org/10.1210/jc.20151715.

59. McClung MR, Brown JP, Diez-Perez A, et al. Effects of 24 months of treatment with romosozumab followed by 12 months of denosumab or placebo in postmenopausal women with low bone mineral density: A randomized, double-blind, phase 2, parallel group study. J Bone Miner
Res 2018;33:1397-406. https://doi.org/10.1002/jbmr.3452.

60. Cosman F, Crittenden DB, Adachi JD, et al. Romosozumab treatment in postmenopausal women with osteoporosis. N Engl J Med 2016;375:1532-43. https://doi.org/10.1056/ NEJMoa1607948.

61. Saag KG, Petersen J, Brandi ML, et al. Romosozumab or alendronate for fracture prevention in women with osteoporosis. N Engl J Med 2017;377:1417-27. https://doi.org/ 10.1056/NEJMoa1708322.

62. Tsourdi E, Yu EW, Jan de Beur SM, et al. Vaccination for coronavirus disease 2019 (COVID-19) and relationship to osteoporosis care: Current evidence and suggested approaches. J Bone Miner Res 2021. https://doi.org/10.1002/ jbmr.4304.

63. Reid IR, Gamble GD, Mesenbrink P, et al. Characterization of and risk factors for the acute-phase response after zoledronic acid. J Clin Endocrinol Metab 2010;95:4380-7. https: //doi.org/10.1210/jc.2010-0597.

64. Diker-Cohen T, Rosenberg D, Avni T, et al. Risk for infections during treatment with denosumab for osteoporosis: A systematic review and meta-analysis. J Clin Endocrinol Metab 2020;105:dgz322. https://doi.org/10.1210/clinem/ dgz322.

65. Bone HG, Wagman RB, Brandi ML, et al. 10 years of denosumab treatment in postmenopausal women with osteoporosis: results from the phase 3 randomised FREEDOM trial and open-label extension. Lancet Diabetes Endocrinol 2017;5:513-23. https://doi.org/10.1016/s2213-8587 (17)30138-9.

66. Kendler DL, Marin F, Zerbini CAF, et al. Effects of teriparatide and risedronate on new fractures in post-menopausal women with severe osteoporosis (VERO): a multicentre, double-blind, double-dummy, randomised controlled trial. Lancet 2018;391:230-40. https://doi.org/10.1016/s01406736(17)32137-2.

67. Kaveh S, Hosseinifard H, Ghadimi N, et al. Efficacy and safety of romosozumab in treatment for low bone mineral density: A systematic review and meta-analysis. Clin Rheumatol 2020;39:3261-76. https://doi.org/10.1007/s10067020-04948-1. 